\title{
Portuguese Validation of the Dissociative Experiences Scale (DES)
}

\author{
HELENA ESPÍRITO SANTO, PsyD \\ Department of Psychology, Instituto Superior Miguel Torga, Coimbra, Portugal \\ JOSÉ LUÍS PIO ABREU, MD, PhD \\ Department of Psychiatry, Hospitais da Universidade de Coimbra, Coimbra, Portugal
}

Objective: The Dissociative Experiences Scale (DES) is a widely used screening tool for dissociative symptoms. The aim of the present study was to evaluate the validity and internal consistency of a Portuguese version and determine if it accurately identified dissociative pathology. Method: The original DES underwent a "forward-backward" translation process. The translated form was used on 570 participants divided into 3 subgroups: 113 patients with dissociative symptoms, 233 psychiatric patients with various psychopathological disorders, and 224 normal individuals. Results: A principal components analysis with all of the participants yielded 4 factors that accounted for $56.3 \%$ of the variance. Reliability as measured by Cronbach's alpha was .94. The receiver operating characteristic curve applied to the cutoff analysis revealed a value of 30 comparing the 2 clinical groups and contrasting the dissociative-based group with the nonclinical group. The ability of the DES to correctly classify those with and without the disease was very good. Sensitivity was $65.0 \%$ and specificity was 86.0\% with the cutoff score of 30 from the comparison between dissociative symptomatic disorders and the other psychopathological disorders. Comparing the dissociative symptomatic group with the nonclinical group, we found that sensitivity was $65.0 \%$ and specificity was 100\%. The mean DES scores for the 3 subgroups were significantly different. Conclusion: These findings are in some degree analogous to those in other studies and suggest that the DES is a reliable and valid screen for the Portuguese population.

Received 17 September 2007; accepted 5 December 2007.

Address correspondence to Helena Espírito Santo, PsyD, Department of Psychology, Instituto Superior Miguel Torga, Rua Augusta 46, 3000-061 Coimbra, Portugal. E-mail: helenum@gmail.com 
KEYWORDS Dissociative Experiences Scale, dissociative disorder, validation study, receiver operating characteristic curve, accuracy

\section{INTRODUCTION}

Dissociation is considered a defensive process in which thoughts, emotions, or sensations fail to be included in the flow of consciousness and memory (E. M. Bernstein \& Putnam, 1986). The clinical attention and investigation dedicated to dissociation is extensive and still growing. Many studies have suggested that dissociation is a significant phenomenon of different pathological disorders, such as posttraumatic stress disorder (PTSD; e.g., Van der Hart, Nijenhuis, \& Steele, 2005), obsessive-compulsive disorder (e.g., Rufer, Fricke, Held, Cremer, \& Hand, 2006), eating disorders (e.g., Lightstone, 2004), pseudoseizure (e.g., Prueter, Schultz-Venrath, \& Rimpau, 2002), substance abuse (e.g., Seedat, Stein, \& Forde, 2003), anxiety and mood disorders, and borderline personality disorder (e.g., Sar et al., 2007).

The Dissociative Experiences Scale (DES) is tool used extensively to screen for dissociative symptoms; it differentiates between dissociative disorder patients and other psychiatric patients, and normal individuals (E. M. Bernstein \& Putnam, 1986; Carlson et al., 1993; Sanders \& Green, 1994). The DES has been studied in several countries and translated into more than 20 languages (Sidran Institute, 2007). The mean scores of the DES are comparable between different countries, indicating the stability of the construct across cultures. The major studies, performed on representative samples of the general population, have estimated mean scores that ranged from $2.3 \pm 4.2$ to $10.8 \pm 20.2$ (Akyüz, Doğan, Sar, Yargic, \& Tutkun, 1999; Ensink \& Van Otterloo, 1989; Maaranen et al., 2005; Modestin \& Erni, 2004; Ross, Joshi, \& Currie, 1990; Ross, Norton, \& Anderson, 1988; C. Spitzer et al., 2006). In dissociative samples, the mean DES scores are higher, ranging from $36.4 \pm 11.7$ to $47.6 \pm 16.3$ (Draijer \& Boon, 1993; Ensink \& Van Otterloo, 1989; Sar et al., 2007). The mean DES scores of clinical samples with other kinds of psychopathology vary from $12.0 \pm 11.4$ to $20.0 \pm 18.1$ (Draijer \& Boon, 1993; Friedl \& Draijer, 2000; Modestin, Ebner, Junghan, \& Erni, 1996; Sar et al., 2007). The DES is a measure with well-established reliability and validity in assessing dissociative disorders. Van IJzendoorn and Schuengel's (1996) revision obtained a mean alpha reliability of .93 from 16 studies. Different investigations have proposed diverse cutoff scores of the DES for uncovering dissociative disorders in clinical samples. Some have suggested a cutoff of 15 (Steinberg, Rounsaville, \& Cicchetti, 1991), some 20 (e.g., Modestin \& Erni, 2004; Seedat et al., 2003), some 25 (e.g., Friedl \& Draijer, 2000; Sar et al., 2007), and yet others have suggested 30 (Carlson et al., 1993; Fleisher et al., 2002). Different studies have obtained solutions with several factors, ranging 
from one up to seven (Amdur \& Liberzon, 1996; I. H. Bernstein, Ellason, Ross, \& Vanderlinden, 2001; Dunn, Ryan, \& Paolo, 1994; Lipsanen, Saarijärvi, \& Lauerma, 2003; Ray, June, Turaj, \& Lundy, 1992; Ross, Ellason, \& Anderson, 1995; Ross et al., 1990; Sanders \& Green, 1994). Using solely the eigenvalues $>1$ as a criterion for structural extraction could be the reason for these differences (Lipsanen et al., 2003); another explanation is the different samples used (clinical and nonclinical).

Although there are a great number of patients with dissociation states in Portuguese psychiatric facilities, the study and use of objective screening procedures is not yet common practice. Thus, the aims of this article are the validation of the scale in Portuguese clinical and nonclinical samples, the verification of its clinical usefulness, and the quantification of dissociative phenomena among different psychopathological disorders.

\section{METHOD}

\section{Participants}

We selected a total of 570 participants from various sources. Participants were recruited from two psychiatric clinics, three psychotherapeutic centers, six college classes, and the general population (students' and colleagues' family and friends). All individuals volunteered to participate, and we gave them feedback from their questionnaires upon request (from an additional personality questionnaire not in this study). Clinicians treating people meeting criteria for the given disorders and judged to be able to comply enrolled consecutive patients from the clinical facilities. Diagnostic validity was ensured by the expertise and years of training of the clinicians (mean practice of 19.7 years), by a longitudinal evaluation using all data available (LEAD methodology; R. L. Spitzer, 1983), and throughout the Dissociative Disorders Interview Schedule (DDIS). Four evaluators carried out the DDIS, including the senior author (J.L.P.A.), the first author (H.E.S), and two clinicians guided in the use of the instrument by the senior author. All of the participants recruited from the general population completed the Brief Symptom Inventory (BSI) to identify the nonclinical participants; the first author carried out an unstructured clinical interview for those with high symptom rates. Afterward, and when justified, the first investigator implemented the DDIS with those participants suspected of having a dissociative disorder. In the end, we divided participants into three subgroups: a group of patients with dissociative symptoms, a comparison group of patients with other symptoms, and a group of people with no significant symptoms.

Clinical group. In all, 113 patients (43 of them inpatients) who had dissociative symptoms were included in the study. Of these patients, 37 had a dissociative disorder (11 patients with depersonalization, 11 with amnesia, 7 with fugue, and 8 with dissociative disorder not otherwise specified), 
50 suffered from PTSD, and 26 were diagnosed with conversion disorder. A total of 33 (29\%) were male and 80 (71\%) female. The mean age was $30.8 \pm 12.3$ years. Fifteen patients were recruited from the general population, but we diagnosed them as having a dissociative disorder based on the clinical interview and the DDIS. We included PTSD in this group, because dissociation is a characteristic psychological process according to several investigations (Amdur \& Liberzon, 1996; Bremner \& Brett, 1997; Carlson \& Putnam, 1993; Van der Hart et al., 2005). We also included conversion disorder in this group, because some studies support the classification of conversion disorders with dissociative disorders (Krüger \& Van Staden, 2003; Nemiah, 1993; Sar, Akyüz, Kundakçı, Kızıltan, \& Doğan, 2004; C. Spitzer, Spelsberg, Grabe, Mundt, \& Freyberger, 1999), and there is no doubt that conversion disorder has an important dissociative component (Guz et al., 2004; Tezcan et al., 2003).

Comparison group. This group comprised 233 patients (42 inpatients): 59 with somatization disorder, 18 with panic disorder, 34 with major depression disorder, 34 with obsessive-compulsive disorder, 60 with social phobia, and 28 with anxiety disorder not otherwise specified. The mean age was $32.7 \pm 12.8$ years, with 79 men (34\%) and 154 women (66\%). None of these patients met criteria for any dissociative, PTSD, or conversion disorder, and they were matched for gender and age.

Nonclinical group. In all, 224 individuals were selected for comparison: 90 of them were male (40\%) and 134 female (60\%), with a mean age $33.0 \pm$ 12.2 years.

The demographic characteristics of the participants of each group are shown in Table 1. There were no significant differences between the three groups on age, $F(2)=1.16, p>.05$, and Bonferroni post hoc multiple comparisons nonsignificant $F(2)=1.16, p>.05(d f=2)$; gender, $\chi^{2}(8)=7.65$,

TABLE 1 Group and Subsample Demographic Characteristics

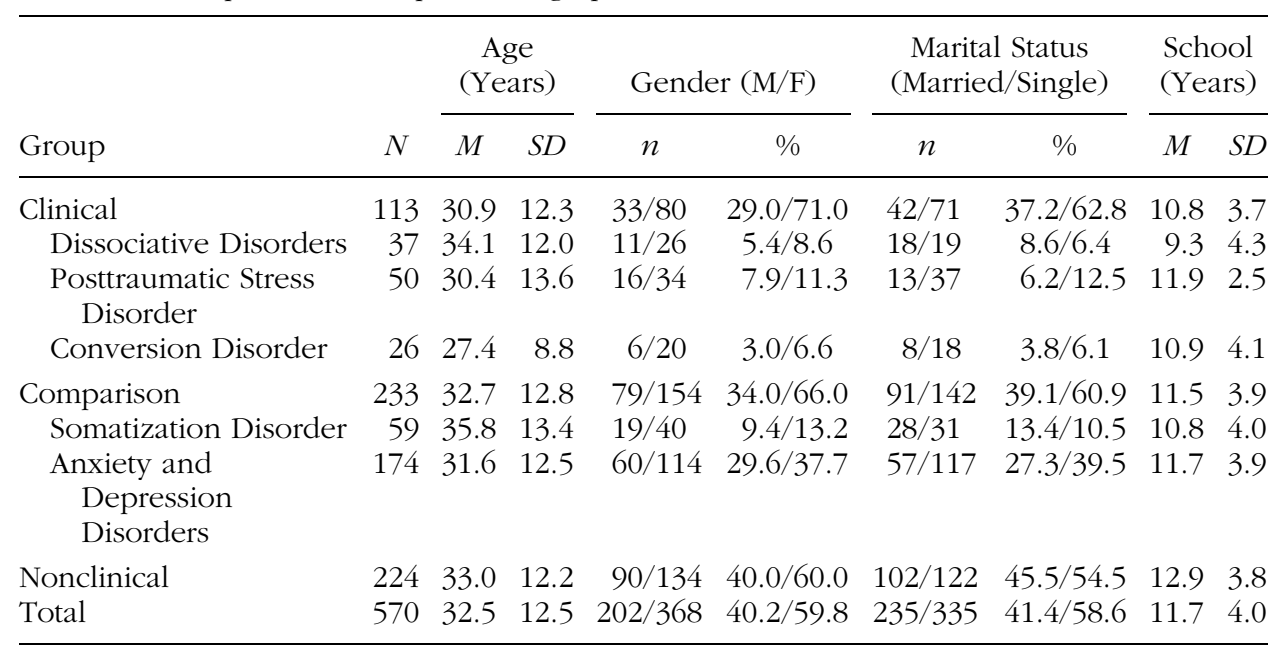


$p>.05(n=570)$; or marital status, $\chi^{2}(2)=2.94, p>.05(n=570)$. The groups differed significantly in number of school years, $F(2)=14.49, p<.001(d f=2)$, with the nonclinical group having more education.

\section{Instruments}

The DES is a self-administered 28-item questionnaire based on Diagnostic and Statistical Manual of Mental Disorders dissociation characterization; it has good reliability and validity, and a strong ability to identify dissociative disorders in a patient population (E. M. Bernstein \& Putnam, 1986; Carlson et al., 1993; Sanders \& Green, 1994). We used the second version of the DES, which has a format of numbers from 0 to 100.

The BSI is a 53-item self-report inventory used to measure current psychological symptoms and distress (Derogatis \& Melisaratos, 1983). The BSI measures nine symptom dimensions and has two general measures of distress: the Global Severity Index and the Positive Symptom Total. The reliability and validity of the Portuguese version of the BSI is similar to that of the original version (Cronbach's alpha for the subscales range from .62 to .80; Canavarro, 1988).

The Portuguese version of the DDIS (Ross et al., 1989) diagnoses all dissociative, somatization, major depression, substance abuse, borderline personality, and conversion disorders meeting Diagnostic and Statistical Manual of Mental Disorders (4th ed.) norms. The Portuguese version of the DDIS had good sensitivity (84\%) and specificity of 100\% (Espirito Santo, Madeira, \& Pio Abreu, 2007).

\section{Procedures}

The translation of the original DES followed a "forward-backward" process (Brislin, Lonner, \& Thorndike, 1973; Carlson \& Putnam, 1993). We did two independent translations of the DES into Portuguese, and, after discussing both of them, we developed a consensual version. We gave the preliminary translation to seven patients to report any problems in comprehending the items. Revisions were made to some sentences. Afterward we submitted the translated copy to a bilingual speaker and to a native Portuguese speaker proficient in English, who blindly back-translated into English. Finally, we compared the original and backtranslated versions, and we modified the wording of an item. All participants gave informed consent (according to the Code of Ethics of the World Medical Association Declaration of Helsinki) and were engaged from 2003 to 2006.

We performed the data analysis with the Statistical Package for the Social Sciences (Mac Os Version 11.0.3). We calculated the means and standard deviations of the DES for patients with dissociative symptoms and for the other two groups. We compared mean scores among the three groups 
by using analysis of variance with Games-Howell post hoc procedure (because of the different-size groups and variances).

We carried out a receiver operating characteristic (ROC) analysis according to the methodology described by Carlson et al. (1993). The ROC analysis has many advantages (Zweig \& Campbell, 1993): It plots sensitivity against 1-specificity for the complete range of decision cutoffs; it makes no parametric assumptions; computation is simple and provides the best assertions of sensitivity, specificity, and area under the curve (AUC); and it is independent of the prevalence of disease. The AUC is an index of the discriminating ability of an assessment tool, and the larger the area, ranging from 0.50 (no discrimination) to 1.0 (perfect discrimination), the better the test. Following the ROC analysis we calculated the best cutoff, which was the one that had good sensitivity and a low false positive rate. After that we determined sensitivity, specificity, positive predictive power (PPP), and negative predictive power (NPP).

We identified the principal factors of the DES by using a principal components analysis (with the Varimax rotation method) with all of the participants. We used the following criteria for determining the number of factors: (a) coherence-we assigned items to factors if they were linked theoretically with other items in the factor (Smith \& McCarthy, 1995); (b) the Kaiser criterion-we dropped all components with eigenvalues less than 1.0; (c) the Scree plot—we eliminated factors after the point where the eigenvalues drop ceased (Zwick \& Velicer, 1986); and (d) we judged items to load onto a factor if they scored 0.45 or greater (Ross et al., 1995). After that, we conducted an analysis of variance of the DES subscales for determination of differences between groups. Finally, we examined reliability, computing the split-half coefficient and Cronbach's alpha.

\section{RESULTS}

\section{Descriptives}

The general DES mean score was $18.81 \pm 13.82$, representing a moderate level of dissociation. The other DES scores are presented in Table 2.

\section{ROC Analysis and Diagnostic Tests}

The ROC analysis for the comparison of dissociative symptomatic patients and comparison participants showed a total AUC of 0.92, which means that the DES has a good ability to correctly classify those with a dissociative symptomatic disease and those with a non-dissociative disorder. The ROC analysis comparing clinical with nonclinical participants revealed a total AUC of 0.97 , indicating that the DES discriminates very well between those with and without a dissociative symptomatic disorder. Comparing the 
TABLE 2 Differences in Mean Scores of the Three Groups in Total and for Each Factor of the Dissociative Experiences Scale (DES)

\begin{tabular}{|c|c|c|c|c|c|c|c|}
\hline \multirow[b]{2}{*}{ Variable } & \multicolumn{2}{|c|}{ Clinical $(n=113)$} & \multicolumn{2}{|c|}{ Comparison $(n=224)$} & \multicolumn{2}{|c|}{ Nonclinical $(n=233)$} & \multirow[b]{2}{*}{$F^{\mathrm{a}}$} \\
\hline & $M \pm S D$ & Range & $M \pm S D$ & Range & $M \pm S D$ & Range & \\
\hline Total DES & $37.68 \pm 13.48$ & 61.48 & $18.63 \pm 10.19$ & 51.85 & $10.02 \pm 6.50$ & 33.00 & $303.12^{\mathrm{b}}$ \\
\hline $\begin{array}{l}\text { Factors } \\
\text { 1. Depersonalization-Derealization } \\
\text { 2. Absorption } \\
\text { 3. Moderate Memory Disturbances } \\
\text { 4. Memory Disturbances }\end{array}$ & $\begin{array}{l}33.10 \pm 20.25 \\
46.65 \pm 17.15 \\
45.66 \pm 15.95 \\
23.26 \pm 16.51\end{array}$ & $\begin{array}{l}72.85 \\
74.29 \\
86.66 \\
80.00\end{array}$ & $\begin{array}{c}10.38 \pm 10.88 \\
27.08 \pm 14.10 \\
25.92 \pm 15.33 \\
9.91 \pm 9.55\end{array}$ & $\begin{array}{l}68.57 \\
67.14 \\
81.67 \\
45.00\end{array}$ & $\begin{array}{c}3.58 \pm 5.34 \\
17.09 \pm 12.70 \\
13.99 \pm 9.31 \\
4.61 \pm 5.72\end{array}$ & $\begin{array}{l}38.57 \\
72.86 \\
48.33 \\
55.00\end{array}$ & $\begin{array}{l}237.16 \\
165.17 \\
209.38 \\
125.99\end{array}$ \\
\hline
\end{tabular}

${ }^{\mathrm{a}} d f=2, p<.0001$.

${ }^{\mathrm{b}}$ Games-Howell post hoc showed significant differences between the clinical and the comparison groups, between the clinical and the nonclinical groups, and between the comparison and nonclinical groups $(p<.001)$. 
clinical with comparison participants, we found the best sensitivity-specificity relation at a cutoff of 30 . The sensitivity index for a cutoff score of 30 was 0.65 , denoting that there is a $65 \%$ chance that a person diagnosed with a dissociative symptomatic disorder will score high on the DES. The specificity index was 0.86 , implying that there is an $86 \%$ chance that a person not having a dissociative disorder will score low. The PPP was 0.70 and refers to the probability that an individual with a score that exceeds the cutoff has a dissociative disorder (true positive), whereas the NPP, which was 0.84, points to the probability that an individual with a score below the cutoff does not have a dissociative disorder. With a cutoff of 25 we would have had a better sensitivity-specificity relation, but the PPP would have been much lower (0.53). From the comparison between clinical and nonclinical participants, we established the best sensitivity-specificity relation at a cutoff of 30. The sensitivity index for a cutoff score of 30 was 0.65 , specificity was 1.00, PPP was 0.99, and NPP was 0.85. Again, the better sensitivityspecificity relation would have been at a cutoff of 25 , but we preferred to lose sensitivity and gain PPP.

The analysis of the frequencies showed that most of the clinical group (66.4\%, $n=75$ ) exceeded the 30 cutoff score, whereas only a small minority of the non-dissociative groups did so (comparison: $14.6 \%, n=34$; nonclinical: $0.9 \% ; n=2)$.

\section{Validity Analysis: Factorial Structure}

The principal components analysis produced a four-factor solution (see Table 3) that accounted for $56.3 \%$ of the variance; thus, factorial validity of the Portuguese version is sufficient. The scree plot test confirmed this structural solution, and the items seemed to us theoretically fitted. We designated the first factor, connected with experiences of feeling disconnected and detached, as Depersonalization-Derealization. The second factor, Absorption, was related to experiences of being absorbed and oblivious to the environment and pain. The third factor comprised experiences of forgetting and confused memories, so we designated it Moderate Memory Disturbances. The fourth, related to Memory Disturbances, involved experiences of memory gaps. We assigned Item 27 ("Voices inside one's head"), which loaded on Factor 1 and Factor 3, to Factor 1 for conceptual coherence (Ross et al., 1995). Item 10 ("Unjustly accused of lying") did not load over 0.45 on any factor and had a low communality (0.369); moreover, the factors on which the variable may load were not conceptually linked. The mean scores of the three groups in each factor differed significantly (see Table 2), with Games-Howell post hoc multiple comparisons revealing that the significant differences were between the three groups. 
TABLE 3 Principal Components Analysis of the Dissociative Experiences Scale (DES) in a Portuguese Sample $(N=570)$

\begin{tabular}{|c|c|c|c|c|c|}
\hline Item & $\begin{array}{c}\text { Total } \\
\text { Variance } \\
\text { Explained } \\
(\%)\end{array}$ & $\begin{array}{l}\text { Factor } \\
\text { Loading }\end{array}$ & $M \pm S D$ & $\begin{array}{l}\text { Corrected } \\
\text { Item } \\
\text { Total }\end{array}$ & $\begin{array}{c}\alpha \text { if } \\
\text { Item } \\
\text { Deleted }\end{array}$ \\
\hline $\begin{array}{l}\text { Factor 1-Depersonalization- } \\
\text { Derealization }(\alpha=.90)\end{array}$ & 15.78 & & & & \\
\hline 12. People and objects seem unreal & & 0.80 & $12.31 \pm 20.37$ & 0.66 & .94 \\
\hline 13. Body feels not one's own & & 0.79 & $9.91 \pm 19.89$ & 0.64 & .94 \\
\hline 28. World seen through a fog & & 0.68 & $13.23 \pm 22.09$ & 0.67 & .94 \\
\hline 11. Not recognizing self in mirror & & 0.68 & $9.18 \pm 17.80$ & 0.63 & .94 \\
\hline 7. Standing beside self & & 0.62 & $12.02 \pm 19.68$ & 0.67 & .94 \\
\hline 16. Familiar place seems unfamiliar & & 0.55 & $16.84 \pm 20.61$ & 0.74 & .94 \\
\hline 27. Voices inside one's head & & 0.53 & $11.85 \pm 22.30$ & 0.62 & .94 \\
\hline Factor 2-Absorption $(\alpha=.83)$ & 14.03 & & & & \\
\hline 23. Difficult things done easily & & 0.65 & $30.62 \pm 23.84$ & 0.54 & .94 \\
\hline 22. Seems to be two people & & 0.64 & $22.45 \pm 23.22$ & 0.61 & .94 \\
\hline 17. Absorption in TV or story & & 0.61 & $31.94 \pm 27.17$ & 0.50 & .94 \\
\hline 18. Fantasy seems real & & 0.61 & $24.35 \pm 25.60$ & 0.67 & .94 \\
\hline 14. Remembering seems real & & 0.54 & $30.87 \pm 27.31$ & 0.57 & .94 \\
\hline 20. Staring into space & & 0.54 & $27.39 \pm 26.09$ & 0.71 & .94 \\
\hline 19. Able to ignore pain & & 0.53 & $21.39 \pm 23.24$ & 0.47 & .94 \\
\hline Factor 3 - Distractibility $(\alpha=.86)$ & 13.71 & & & & \\
\hline 25. Not remembering doing things & & 0.67 & $22.20 \pm 24.00$ & 0.76 & .94 \\
\hline $\begin{array}{l}\text { 24. Uncertainty about doing } \\
\text { something }\end{array}$ & & 0.65 & $30.53 \pm 26.09$ & 0.71 & .94 \\
\hline $\begin{array}{l}\text { 26. Not remembering doing } \\
\text { annotations }\end{array}$ & & 0.64 & $17.62 \pm 22.12$ & 0.64 & .94 \\
\hline 1. Not remembering driving & & 0.64 & $22.95 \pm 21.48$ & 0.58 & .94 \\
\hline 2. Missing part of a conversation & & 0.58 & $33.21 \pm 22.63$ & 0.54 & .94 \\
\hline $\begin{array}{l}\text { 15. Not sure if an event was a } \\
\text { dream }\end{array}$ & & 0.46 & $24.44 \pm 23.76$ & 0.69 & .94 \\
\hline 21. Talking when alone & & 0.46 & $25.26 \pm 26.87$ & 0.53 & .94 \\
\hline $\begin{array}{l}\text { Factor } 4 \text {-Memory Disturbances } \\
\quad(\alpha=.80)\end{array}$ & 12.75 & & & & \\
\hline 5. Unfamiliar belongings & & 0.69 & $10.14 \pm 17.06$ & 0.51 & .94 \\
\hline 3. Unaware of getting to a place & & 0.64 & $11.30 \pm 19.23$ & 0.61 & .94 \\
\hline $\begin{array}{l}\text { 8. Not recognizing friends or } \\
\text { relatives }\end{array}$ & & 0.63 & $8.35 \pm 15.63$ & 0.49 & .94 \\
\hline 4. Not remembering dressing & & 0.60 & $5.99 \pm 13.43$ & 0.60 & .94 \\
\hline 6. Called by another name & & 0.57 & $14.07 \pm 18.31$ & 0.42 & .94 \\
\hline $\begin{array}{l}\text { 9. Not remembering important } \\
\text { events }\end{array}$ & & 0.57 & $12.93 \pm 19.52$ & 0.52 & .94 \\
\hline \multicolumn{6}{|l|}{ Other } \\
\hline 10. Unjustly accused of lying & & 0.38 & $13.14 \pm 17.04$ & 0.54 & .94 \\
\hline
\end{tabular}

Notes: The factor-item correlations, the item characteristics, and the reliability of the DES are shown. Extraction method: principal components analysis. Rotation method: varimax with Kaiser normalization. DES $\alpha=.94$. 


\section{Reliability Analysis: Internal Consistency}

Results showed very high item-total correlations. Item statistics are outlined in Table 3. Internal consistency measured by split-half was .81 and by Cronbach's alpha was .94, indicating good reliability.

\section{DISCUSSION}

The Portuguese DES seems to be a good screen for dissociative symptoms, and for discrimination between dissociative patients (depersonalization, amnesia, fugue, dissociative disorder not otherwise specified, PTSD, and conversion disorders) and other psychiatric patients (somatization, panic, obsessive-compulsive disorder, depression, and anxiety not otherwise specified) and nonclinical individuals. The mean DES score was higher in the dissociative symptomatic group compared with both the nonclinical group and the group with other pathologies. The mean DES scores in the three groups were similar to those of other studies that analyzed dissociative disorders (Draijer \& Boon, 1993; Ensink \& Van Otterloo, 1989; Sar et al., 2007), studies that investigated other psychiatric disorders (Draijer \& Boon, 1993; Friedl \& Draijer, 2000; Modestin et al., 1996; Sar et al., 2007), and investigations with nonclinical groups (Akyüz et al., 1999; Ensink \& Van Otterloo, 1989; Maaranen et al., 2005; Modestin \& Erni, 2004; Ross et al., 1988, 1990; C. Spitzer et al., 2006). As with these investigations, the standard deviations were high, possibly due in part to comorbidity, which was not controlled in this study. In favor of this supposition is the difference between the mean DES scores of the comparison group and the dissociative group.

The ROC analysis indicates that the DES is a fine screening tool and that the best equilibrium between sensitivity and specificity happens at a cutoff score of 30 . The Portuguese version also seems valuable for understanding cultural influences and tracking the concept of dissociation as it alters. In fact, our factor structure was different from that of other studies, with the exception of two studies (Amdur \& Liberzon, 1996; Dunn et al., 1994), although our version has four factors with similarities in their content to other studies (Amdur \& Liberzon, 1996; Dunn et al., 1994; Ross et al., 1990). The factors also discriminated between groups: The clinical group scored higher on each factor than the comparison group. Nevertheless, some reservations are worth noting. Cronbach's alphas of the Absorption and Memory Disturbances subscales were less than .85, which means we cannot consider these factors as a pathological equivalents. Only $56.3 \%$ of total variance was accounted for, which restricts the capability of the factors to explain the structure of the DES (Dunn et al., 1994). Global scale reliability analysis, however, showed good internal consistency; thus, we can 
assume that the questions converge on the same construct and that the DES is a unified scale of dissociation.

Our results join the growing number of studies using the DES in Europe and America, but our research has some limitations. Although our three groups were balanced for gender and age distribution, women predominated. In addition, the clinical group had a lower educational level, and, despite the fact that most studies have not shown any significant effect (Akyüz et al., 1999; Boon \& Draijer, 1991; Ross et al., 1990), one study revealed that a higher educational level correlated with a lower intensity of dissociation (Dunn, Paolo, Ryan, \& Van Fleet, 1993). Finally, we used convenience samples that were not representative of the Portuguese population. However, most of the studies we analyzed also used samples that did not represent their populations, except for Maaranen et al. (2005), Ross et al. (1990), and Seedat et al. (2003).

Despite the limitations of this study, we conclude that the Portuguese version of the DES is a reliable and valid measure in screening for dissociative experiences and detecting dissociative disorders or disorders with a dissociative component. Dissociation remains a valid construct that cuts across cultures and time periods.

\section{REFERENCES}

Akyüz, G., Doğan, O., Sar, V., Yargic, L. I., \& Tutkun, H. (1999). Frequency of dissociative identity disorder in the general population in Turkey. Comprehensive Psychiatry, 40(2), 151-159.

Amdur, R. L., \& Liberzon, I. (1996). Dimensionality of dissociation in subjects with PTSD. Dissociation, 9(2), 118-124.

Bernstein, E. M., \& Putnam, F. W. (1986). Development, reliability and validity of a dissociation scale. Journal of Nervous and Mental Disease, 174, 727-735.

Bernstein, I. H., Ellason, J. W., Ross, C. A., \& Vanderlinden, J. (2001). On the dimensionalities of the Dissociative Experiences Scale (DES) and the Dissociation Questionnaire (DIS-Q). Journal of Trauma E Dissociation, 2(3), 103-123.

Boon, S., \& Draijer, N. (1991). Diagnosing dissociative disorders in the Netherlands: A pilot study with the structured interview for DSM-III-R dissociative disorders. American Journal of Psychiatry, 148, 458-462.

Bremner, J. D., \& Brett, E. (1997). Trauma-related dissociative states and long-term psychopathology in posttraumatic stress disorder. Journal of Traumatic Stress, 10, 37-49.

Brislin, R., Lonner, W., \& Thorndike, R. (1973). Cross-cultural research methods. New York: Wiley.

Canavarro, M. C. (1988). Inventário de Sintomas psicopatológicos (Psychopathological symptoms inventory). In M. R. Simões, M. M. Gonçalves, \& L. S. Almeida (Eds.), Testes e provas psicológicas em Portugal (Vol. 26, pp. 95-109). Braga, Portugal: APPORT. 
Carlson, E. B., \& Putnam, F. W. (1993). An update of the Dissociative Experience Scale. Dissociation, 6(1), 16-27.

Carlson, E. B., Putnam, F. W., Ross, C. A., Torem, M., Coons, P., Dill, D. L., et al. (1993). Validity of the Dissociative Experiences Scale in screening for multiple personality disorder: A multicenter study. American Journal of Psychiatry, 150, 1030-1036.

Derogatis, L. R., \& Melisaratos, N. (1983). The Brief Symptom Inventory: An introductory report. Psychological Medicine, 13, 595-605.

Draijer, N., \& Boon, S. (1993). Validation of the Dissociative Experiences Scale against the criterion of the SCID-D using receiver operating characteristics (ROC) analysis. Dissociation, 6(1), 28-37.

Dunn, G. E., Paolo, A. M., Ryan, J. J., \& Van Fleet, J. (1993). Dissociative symptoms in a substance abuse population. American Journal of Psychiatry, 150, 1043-1047.

Dunn, G. E., Ryan, J. J., \& Paolo, A. M. (1994). A principal component analysis of the Dissociative Experiences Scale in a substance abuse population. Journal of Clinical Psychology, 50, 936-941.

Ensink, B. J., \& Van Otterloo, D. (1989). A validation study of the DES in the Netherlands. Dissociation, 2(4), 221-223.

Espirito Santo, H. M. A., Madeira, F., \& Pio Abreu, J. L. (2007). Versão portuguesa do Dissociative Disorders Interview Schedule (DDIS-P). Estudo preliminar de adaptação a uma amostra da população Portuguesa (DDIS, Portuguese version. Preliminary study of adaptation to a Portuguese sample). Revista de Psiquiatria Clinica, 28, 5-17.

Fleisher, W., Staley, D., Krawetz, P., Pillay, N., Arnett, J. L., \& Maher, J. (2002). Comparative study of trauma-related phenomena in subjects with pseudoseizures and subjects with epilepsy. American Journal of Psychiatry, 159, 660-663.

Friedl, M. C., \& Draijer, N. (2000). Dissociative disorders in Dutch psychiatric inpatients. American Journal of Psychiatry, 157, 1012-1013.

Guz, H., Doganay, Z., Ozkan, A., Colak, E., Tomac, A., \& Sarisoy, G. (2004). Conversion and somatization disorders: The dissociative symptoms and other characteristics. Journal of Psychosomatic Research, 56, 287-291.

Krüger, C., \& Van Staden, W. (2003). Is conversion a dissociative symptom? Bridging Eastern and Western Psychiatry, 1(1), 88-94.

Lightstone, J. (2004). Dissociation and compulsive eating. Journal of Trauma $\varepsilon$ Dissociation, 5(4), 17-32.

Lipsanen, T., Saarijärvi, S., \& Lauerma, H. (2003). The Finnish version of the Dissociative Experiences Scale-II (DES-II) and psychiatric distress. Nordic Journal of Psychiatry, 57(1), 17-22.

Maaranen, P., Tanskanen, A., Honkalampi, K., Haatainen, K., Hintikka, J., \& Viinamäki, H. (2005). Factors associated with pathological dissociation in the general population. Australian and New Zealand Journal of Psychiatry, 39, 387-394.

Modestin, J., Ebner, G., Junghan, M., \& Erni, T. (1996). Dissociative experiences and dissociative disorders in acute psychiatric inpatients. Comprehensive Psychiatry, 37(5), 355-361.

Modestin, J., \& Erni, T. (2004). Testing the dissociative taxon. Psychiatry Research, $126,77-82$. 
Nemiah, J. C. (1993). Dissociation, conversion, and somatization. In D. Spiegel, R. P. Kluft, R. J. Loewenstein, J. C. Nemiah, F. W. Putnam, \& M. Steinberg (Eds.), Dissociative disorders: A clinical review (pp. 104-117). Lutherville, MD: Sidran Press.

Prueter, C., Schultz-Venrath, U., \& Rimpau, W. (2002). Dissociative and associated psychopathological symptoms in patients with epilepsy, pseudoseizures, and both seizure forms. Epilepsia, 43(2), 188-192.

Ray, W. J., June, K. I., Turaj, K., \& Lundy, R. (1992). Dissociative experiences in a college age population: A factor analytic study of two dissociation scales. Personality and Individual Differences, 13, 417-424.

Ross, C. A., Ellason, J. W., \& Anderson, G. (1995). A factor analysis of the Dissociative Experiences Scale in dissociative identity disorder. Dissociation, 8(1), 229-235.

Ross, C. A., Heber, S., Norton, G. R., Anderson, G., Anderson, D., \& Barchet, P. (1989). The Dissociative Disorders Interview Schedule: A structured interview. Dissociation, 2(3), 169-189.

Ross, C. A., Joshi, S., \& Currie, R. (1990). Dissociative experiences in the general population. American Journal of Psychiatry, 147, 1547-1552.

Ross, C. A., Norton, G. R., \& Anderson, G. (1988). The Dissociative Experiences Scale: A replication study. Dissociation, 1(3), 21-22.

Rufer, M., Fricke, S., Held, D., Cremer, J., \& Hand, I. (2006). Dissociation and symptom dimensions of obsessive-compulsive disorder: A replication study. European Archives of Psychiatry and Clinical Neuroscience, 256(3), 146-150.

Sanders, B., \& Green, J. A. (1994). The factor structure of the Dissociative Experiences Scale in college students. Dissociation, 7(1), 23-27.

Sar, V., Akyüz, G., Kundakçı, T., Kızıltan, E., \& Doğan, O. (2004). Childhood trauma, dissociation, and psychiatric comorbidity in patients with conversion disorder. American Journal of Psychiatry, 161, 2271-2276.

Sar, V., Koyuncu, A., Ozturk, E., Yargic, L. I., Kundakci, T., Yazici, A., et al. (2007). Dissociative disorders in the psychiatric emergency ward. General Hospital Psychiatry, 29, 45-50.

Seedat, S., Stein, M. B., \& Forde, D. R. (2003). Prevalence of dissociative experiences in the community sample: Relationship to gender, ethnicity, and substance use. Journal of Nervous and Mental Disease, 191, 115-120.

Sidran Institute. (2007). The Dissociative Experiences Scale, II. Retrieved August 19, 2007, from www.sidran.org/store/index.cfm?fuseaction=product.display\& Product_ID $=62$

Smith, G. T., \& McCarthy, D. M. (1995). Methodological considerations in the refinement of clinical assessment instruments. Psychological Assessment, 7, 300-308.

Spitzer, C., Barnow, S., Grabe, H.-J., Klauer, T., Stieglitz, R.-D., Schneider, W., et al. (2006). Frequency, clinical and demographic correlates of pathological dissociation in Europe. Journal of Trauma \& Dissociation, 7(1), 51-56.

Spitzer, C., Spelsberg, B., Grabe, H.-J., Mundt, B., \& Freyberger, H. J. (1999). Dissociative experiences and psychopathology in conversion disorders. Journal of Psychosomatic Research, 46(3), 291-294.

Spitzer, R. L. (1983). Psychiatric diagnosis: Are clinicians still necessary? Comprehensive Psychiatry, 24(5), 399-411. 
Steinberg, M., Rounsaville, B., \& Cicchetti, D. (1991). Detection of dissociative disorders in psychiatric patients by a screening instrument and a structured diagnostic interview. American Journal of Psychiatry, 148, 1050-1054.

Tezcan, E., Atmaca, M., Kuloglu, M., Gecici, O., Buyukbayram, A., \& Tutkun, H. (2003). Dissociative disorders in Turkish inpatients with conversion disorder. Comprehensive Psychiatry, 44(4), 324-330.

Van der Hart, O., Nijenhuis, E. R. S., \& Steele, K. (2005). Dissociation: An insufficiently recognized major feature of complex posttraumatic stress disorder. Journal of Traumatic Stress, 18, 413-423.

Van IJzendoorn, M. H., \& Schuengel, C. (1996). The measurement of dissociation in normal and clinical populations: Meta-analytic validation of the Dissociative Experiences Scale. Clinical Psychology Review, 16(5), 365-382.

Zweig, C. H., \& Campbell, G. (1993). Receiver-operating characteristic (ROC) plots: A fundamental evaluation tool in clinical medicine. Clinical Chemistry, 39, 561-577.

Zwick, R., \& Velicer, W. F. (1986). Comparison of five rules for determining the number of components to retain. Psychological Bulletin, 99, 432-442. 